CIRJE-F-1026

\title{
Industrial Structure in Urban Accounting
}

\author{
Jun Oshiro \\ Okinawa University \\ Yasuhiro Sato \\ The University of Tokyo
}

October 2016

CIRJE Discussion Papers can be downloaded without charge from:

http://www.cirje.e.u-tokyo.ac.jp/research/03research02dp.html

Discussion Papers are a series of manuscripts in their draft form. They are not intended for circulation or distribution except as indicated by the author. For that reason Discussion Papers may not be reproduced or distributed without the written consent of the author. 


\title{
Industrial Structure in Urban Accounting*
}

\author{
Jun Oshiro and Yasuhiro Sato
}

October 17, 2016

\begin{abstract}
We develop a multisector general equilibrium model of a system of cities to study the quantitative significance of industrial structure in determining spatial structure. We first identify three types of wedges that capture the extent to which the standard urban economic model fails to explain empirically: efficiency and labor wedges, and amenity. We then calibrate the model to Japanese regional data and run counterfactual exercises to identify the significance of each wedge in each sector. Our analysis shows (i) that the labor wedge plays the primary role in determining the spatial structure, and (ii) that the secondary sector is the most influential.
\end{abstract}

Keywords: Urban accounting; Industrial structure; System of cities; Agglomeration

\section{Introduction}

We identify the dominant industry in determining the population distribution in Japan. As Fujita and Tabuchi [19] and Fujita et al. [18] showed regarding Japan in the Post-World War II era, industrial structure has been one of the dominant factors that determine spatial distribution of population. For instance, Japan experienced urbanization in accordance with a secular transition from an agrarian economy to industrialized one. The rise of service industries fueled by technological change and globalization proceeded along with salient agglomeration in the Tokyo metropolitan area. Despite these apparent relationship, it is not yet clear which industry plays a key role in forming spatial configurations. The question of this paper is how important each industry is in shaping the spatial distribution of population.

For this purpose, we extend an urban accounting model of a system of cities developed by Desment and Rossi-Hansberg [11] by introducing multiple industries. An urban accounting model, which is analogous to business cycle accounting models à la Chari, Kehoe, and McGrattan [8], assumes wedges in summarizing the observed regional characteristics that a simple and competitive urban economic model fails to capture. Following Desmet

\footnotetext{
*Jun Oshiro, Department of Law and Economics, Okinawa University, 555 Kokuba, Naha, Okinawa, Japan (j-oshiro@okinawa-u.ac.jp). Yasuhiro Sato, Faculty of Economics, University of Tokyo, 7-3-1, Hongo, Bunkyo-ku, Tokyo, Japan (ysato@e.u-tokyo.ac.jp).

${ }^{\dagger}$ This study is conducted as a part of the Project "Spatial Economic Analysis on Trade and Labor Market Interactions in the System of Cities" undertaken at Research Institute of Economy, Trade and Industry(RIETI). We thank Tomoru Hiramatsu, Tomoya Mori, Özge Öner, and Takaaki Takahashi for their helpful suggestions and comments. We are grateful to participants at Chukyo University. Keio University, Kagawa University, Osaka University, and the 55th annual meeting of Western Regional Science Association in Hawaii.
} 
and Rossi-Hansberg [11], we introduce three types of wedges: the first type, called efficiency wedge, is the revenue-based total factor productivity; the second type, labor wedge, is the gap between the marginal product of labor and the marginal rate of substitution between leisure and consumption; the third type, amenity, is treated as a region-specific residual. These wedges can be used to measure regional characteristics, involving production, consumption, employment, and population, explained by underlying distortions on optimized behavior by agents. The advantage of this method lies in the fact that the model can assess the quantitative importance of a broad class of distortions by inspecting the relationships between wedges and regional characteristics. In addition, the model allows its application potentially to a wide range of policy simulations.

Our study proceeds in several steps. First, we construct a multiple-sector general equilibrium model of a system of cities. A property of equilibrium is analogous to that in Henderson [24] where the size of a region reflects the balance of agglomeration and dispersion forces. Next, we calibrate wedges to match Japanese prefercture-level data. While the data is based on a coarser spatial scale than metropolitan area, we can utilize consistent long-term information at the sectoral level. We characterize industrial structure of regions by exploiting across-region variations in wedges. Finally, to quantify how the industrial structure relates to the spatial structure, we compute the equilibrium distributions of population under several counterfactual scenarios that hypothetically change wedges.

We find that labor wedge is the most responsible for shaping the pupulation distribution in Japan. The efficiency wedge comes the second, and the amenity is least significant. Because the labor wedge captures agglomeration externatilies/disexternalities and the efficiency wedge should reflect productivity and demand, the Japanese urban system is more likely to be explained by external effects than by demand and supply structure. Moreover, our analysis on each industry shows that the secondary sector, which includes the manufacturing sector, plays a key role in determining the Japanese spatial structure. We also show that declines in productivity and hence the efficiency wedge of the primary sector during the past several decades had major impacts on the Japanese spatial structure.

The article most closely related to ours is Desmet and Rossi-Hansberg [11], which have developed urban accounting procedure and applies it to the United States and Chinese urban systems. They have shown that a capability of cities to manage congestion externalities, which is captured by labor wedge, is a key driver for the uneven distribution of population, which is common to our results. However, we observe the following difference: whereas their counterfactual exercise reveals that the elimination of labor wedge differences brings about dispersion of population, our exercise suggests the contrary, with population becoming more concentration by such elimination. Moreover, we uncover the dominant industry in determining the population distribution, which is not explored by Desmet and Rossi-Hansberg [11].

This paper is also related to the following two strands of literature on city size distribution. One is the structural estimation of models of city size distribution. The existing studies in this strand structurally estimated models having explicit structure of agglomeration externalities and disexternalities, and then conducted counterfactuals. ${ }^{1}$ Their analyses naturally hinge on the assumption regarding the explicit structure. In contrast, urban accounting models assume "wedges" that can be interpreted in various ways and decompose the determinants of distribution into a few sources. Because we are uncertain a priori about which would be the suitable explicit structure in capturing the agglomeration

\footnotetext{
${ }^{1}$ See $\mathrm{Au}$ and Henderson [3] and Behrens et al. [5].
} 
forces, we believe that the method employed in urban accounting is reasonable and can complement the existing studies on structural estimation of city size distribution. The other related strand is on empirical regularity in size distribution of cities, well-known as the rank-size rule or the Zipf's law. The body of work in random growth theory shows that location-specific productivity has been regarded as a key determinant for city-size distribution. ${ }^{2}$ By contrast, in this paper labor market and land market play a crucial role in determining the observed rank-size relationship.

The elements of the model are described in Section 2. Section 3 documents data and calibration. Section 4 reports the results of counterfactual simulations. Section 5 concludes.

\section{Baseline framework}

We exend the framework developed by Desmet and Rossi-Hansberg [11] by introducing multi-industries in each region. Consider a competitive economy with $I$ regions, indexed by $i(=1, . ., I)$. Each region hosts one final good sector and $J$ intermediate good sectors, indexed by $j(=1, . ., J){ }^{3}$ The final good is the numèraire, can be freely traded across regions, and be produced using the intermediate goods under constant returns to scale technology. The intermediate goods are not traded across regions.

Each intermediate sector produces according to the Cobb-Douglas technologies:

$$
Y_{i j t}=A_{i j t} K_{i j t}^{\theta_{j}} H_{i j t}^{1-\theta_{j}},
$$

where $Y_{i j t}$ is output, $A_{i j t}$ represents productivity, and $K_{i j t}$ and $H_{i j t}$ denote capital and sector-specific labor inputs, respectively. Time is discrete and is denoted by $t . \theta_{j} \in(0,1)$ is the capital share. Since both capital and labor trade in competitive markets, equilibrium factor prices are given as

$$
w_{i j t}=\left(1-\theta_{j}\right) \frac{P_{i j t} Y_{i j t}}{H_{i j t}}, \quad r_{i t}=\theta_{j} \frac{P_{i j t} Y_{i j t}}{K_{i j t}},
$$

where $P_{i j t}$ is the price of the $j$ sector's good, and $w_{i j t}$ is the return to a unit of sector $j$-specific labor. Capital is assumed to be freely mobile across sectors so that the rate of return on capital in region $i$ is equalized across sector and is denoted by $r_{i t}$.

\subsection{Households and urban structure}

We follow a long tradition of urban economics in assuming the monocentric city structure à la Alonso [2]: Production occurs at the central area of each region where $N_{i t}$ identical households are commuting from their residences to the central area. We adopt the large family assumption under which each household contains one unit of $J$ type of differentiated labor, provides it for each sector, and pools the income. For simplicity, we assume that each household consumes one unit of land per period. In addition, we assume that a household maximizes a present value of the utility stream, $\sum_{t=0}^{\infty} \beta^{t} u_{i t}$, with the following instantaneous utility:

$$
u_{i t}=\log c_{i t}+\psi \sum_{j=1}^{J} \log \left(1-h_{i j t}\right)+\gamma_{i},
$$

\footnotetext{
${ }^{2}$ Gabaix [20], Eeckhout [15], Duranton [13], and Rossi-Hansberg and Wright [31] are classic references. The view is challenged by Berliant and Watanabe [6]. Duranton and Puga [14] gives a recent survey.

${ }^{3}$ In contrast to the traditional system of cities framework à la Henderson [24], we implicitly exclude the possibility of complete specialization.
} 
where $c_{i t}>0$ is the numèraire consumption, $h_{i j t} \in(0,1)$ is the labor supply to sector $j$, $\beta \in(0,1)$ is the time discount rate, $\psi>0$ is the parameter of disutility from working, and $\gamma_{i}$ is the location-specific amenity.

At period $t$, a household faces the following budget constraint.

$$
a_{i t+1}=\left(1+r_{i t}-\delta\right) a_{i t}-c_{i t}+\sum_{j=1}^{J}\left(1-\tau_{i j t}\right) w_{i j t} h_{i j t}+\omega_{i t} .
$$

Here, $a_{i t}$ denotes per household assets held at the beginning of the period $t$ with $a_{i 0}$ being given, and $\delta$ is the depreciation rate. $\omega_{i t}$ is the composite of the lump-sum transfer, payment for land rent and commuting cost, which will be independent of location within the region. $\tau_{i j t}<1$ is tax-equivalent distortion on labor earnings and will be transferred to the residents in a lump-sum way. We call $\tau_{i j t}$ the labor wedge that represents the overall distortion to the household's choice regarding consumption and leisure. Households take both the labor wedge and the transfers as given. The labor wedge could be tax system, labor market institution (Cole and Ohanian [10]; Ohanian [29]), sticky wage and monetary shocks (Chari, Kehoe, and McGrattan [8]), matching friction (Cheremukhin and RestrepoEchavarria [9]), or financial friction (Buera and Moll [7]). The labor wedge also reflects unmeasured differences in taste for sector-specific labor supply since the preference for leisure is treated as symmetry in (3) (i.e., $\psi_{j}=\psi$ for all $j$ ).

The labor wedge is also consistent with models of system of cities (Henderson [24]; Rossi-Hansberg and Wright [31]). Suppose, for instance, that the production function has a term representing the Marshallian externalities as $Y_{i j t}=A_{i j t} K_{i j t}^{\theta_{j}}\left[g\left(\bar{H}_{i j t}, N_{i t}\right) H_{i j t}\right]^{1-\theta_{j}}$. Here, $\bar{H}_{i j t}$ represents the total labor demand in sector $j$ in region $i$, and firms regard $\bar{H}_{i j t}$, and $N_{i t}$ in the function $g$ as fixed. Because we consider a representative firm, in equilibrium, we have $H_{i j t}=\bar{H}_{i j t}$. Profit maximizing developers offer local households a specific level of utility and organize fiscal instruments that internalize the externalities. A Pigouvian subsidy, which is observationally equivalent to the labor wedge, is set to the elasticity of the Marshallian externality to labor supply, $\tau_{i j t}=-g_{H} H_{i j t} / g$ (Appendix A shows this in more general environments). In addition, the labor wedge can be found in traditional urbanization models with unemployment initiated by Harris and Todaro [22] in which households in a city face the expected wage that equals ( 1 - unemployment rate) $\times w_{i j t}$.

Let $z \in \mathbf{R}_{+}$denote the distance from the household's residence to the center of the region. The commuting cost of a household residing at distance $z$ is $z T\left(N_{i t}\right)$ in terms of the numèraire. The function $T: \mathbf{R}_{+} \mapsto \mathbf{R}_{++}$allows region-wide net externalities of agglomeration via congestion or sharing public infrastructure. Households are costlessly mobile within region and thus the land rent per unit of land at $z$, denoted by $R(z)$, is given by $R(z)=(\bar{z}-z) T(N)$ for all $z \in[0, \bar{z}]$, where $\bar{z}$ is the distance to urban boundary from the center of the region. The land rent outside of the urban boundary is normalized to be zero.

Let $n(z) \in R_{+}$be the population density of available land at $z$ in each region. $n(z)$ is assumed to be proportional to $z$, which implies that regions spread sectorally or circularly over two-dimensional space. The population in region $i$ satisfies $N_{i t}=\int_{0}^{\bar{z}} n(z) \mathrm{d} z$. The total commuting cost is given by $T C C_{i t}=\int_{0}^{\bar{z}} z T(N) n(z) \mathrm{d} z$, yielding the total land rent as $T R L_{i t}=\int_{0}^{\bar{z}} R(z) n(z) \mathrm{d} z=\bar{z} T(N) N-T C C_{i t}$. From the assumption of proportionality of $n(z)$ to $z$, we know that

$$
2 T L R_{i t}=T C C_{i t}
$$


Given the linear commuting technology assumption, we can inference the urban cost per household by using the information of total land rents although we cannot directly observe the total commuting cost in a region. ${ }^{4}$

Land is owned by the residents and thus the land rent in each region is redistributed to the residents in the region, as assumed in Michaels, Rauch, and Redding [28]. The non-wage income $\omega_{i t}$ is given by

$$
\omega_{i t}=\sum_{j} \tau_{i j t} w_{i j t} h_{i j t}-2 \frac{T L R_{i t}}{N_{i t}}
$$

The first term is the transfer from the labor wedge. The second term is the net urban cost per household - the sum of land rent and commuting cost minus the land rent revenue. We ignore crossownership of land as well as inter-regional redistribution of wealth.

We allow the labor wedge to vary with size of the region through certain agglomeration externalities and consider the following specification:

$$
1-\tau_{i j t}=\left(1-\tilde{\tau}_{i j t}\right) N_{i t}^{\iota}
$$

That is, the level of labor wedge now depends not only on the exogenous region-sector specific wedge, $\tilde{\tau}_{i j t}$, but also on the population with the elasticity $\iota \in \mathbf{R}$. This specification is motivated by Desmet and Rossi-Hansberg [11] in which the labor wedge increases with the total commuting costs in a region and therefore with population. ${ }^{5}$ The parameter $\iota$ measures the elasticity of externalities with respect to population size, which is assumed to be common for all regions. Appendix $\mathrm{C}$ gives details in the differences between Desmet and Rossi-Hansberg [11] and us. The specification of labor wedge may be analogous to a Harris and Todaro economy in which unemployment rates depend on the population.

\subsection{Steady state equilibrium}

We impose $r_{i t}=\delta+\rho$ for all $i$ and $t$, where $\rho=\beta^{-1}-1$, to ensure that both consumption and asset are constant over time, i.e., $c_{i t+1}-c_{i t}=a_{i t+1}-a_{i t}=0 .{ }^{6}$ Henceforth, when possible, we omit time subscript. In a steady state, the capital-labor ratio, denoted by $\kappa_{i j}$, is given by

$$
\kappa_{i j}=\frac{K_{i j}}{H_{i j}}=\left(\frac{\theta_{j} P_{i j} A_{i j}}{\delta+\rho}\right)^{1 /\left(1-\theta_{j}\right)} .
$$

$P_{i j} A_{i j}$ in the right hand side represents the total factor revenue productivity (TFPR) which we call the efficiency wedge as in Foster, Haltiwanger, and Syverson [17] and Hsieh and Klenow [25]. We focus on TFPR that captures profitability rather than the familiar total factor productivity, $A_{i j}$. Although we can solve $P_{i j}$ by specifying the production technology of the final good sector, it is difficult to credibly identify them from available data. The efficiency wedge could reflect not only productivity in the sector but also relative

\footnotetext{
${ }^{4}$ If the density function $n(d)$ is independent of $d$, e.g., one dimensional linear cities, (5) becomes as $T L R_{i t}=T C C_{i t}$. In this case, dispersion force becomes weaker than that in the benchmark specification. Still, the qualitative and quantitative results would be hardly affected. The linear assumption we use is employd by several studies including Rossi-Hansberg and Wright [31] and Desmet and Rossi-Hansberg [11].

${ }^{5}$ If we ignore externalities in the labor wedge, the dispersion force becomes so weak that only a $1 \%$ change in amenity level, for example, causes extreme agglomeration where no one lives in the most of the regions.

${ }^{6}$ Desmet and Rossi-Hansberg [11] instead set $r_{i t}=\delta$. However, if doing so, the transversality condition will be violated.
} 
demand to the sector that the relative price should reflect. Note also that total factor productivity may capture agglomeration forces as an externality discussed by Rosenthal and Strange [30]. ${ }^{7}$

The intratemporal optimization of households implies that marginal rate of substitution between labor and consumption must be equal to the net-tax marginal product of labor, that is,

$$
\frac{\psi c_{i}}{1-h_{i j}}=\left(1-\tau_{i j}\right) w_{i j}
$$

From the asset market clearing condition, $a_{i} N_{i}=\sum_{j} K_{i j}$, the steady-state budget constraint becomes as

$$
c_{i}=\rho \sum_{j} \kappa_{i j} h_{i j}+\sum_{j} w_{i j} h_{i j}-2 \frac{T L R_{i}}{N_{i}} .
$$

Combining the first-order condition (8), we have

$$
c_{i}=\left[1+\psi \sum_{j} \frac{w_{i j}+\rho \kappa_{i j}}{\left(1-\tau_{i j}\right) w_{i j}}\right]^{-1}\left[\sum_{j}\left(w_{i j}+\rho \kappa_{i j}\right)-2 \frac{T L R_{i}}{N_{i}}\right] .
$$

In equilibrium, the mass of households living in region $i, N_{i}$, is determined by the utility arbitrage. Hence, the utility level becomes equal across regions. Letting $\bar{u} \in R$ be the equilibrium utility level, we obtain

$$
u_{i}=\bar{u} \text { for } N_{i} \geq 0
$$

We set $N_{i}=0$ if $\max _{N_{i} \in \mathbf{R}_{+}} u_{i}<\bar{u}$. The population constraint in the national level is given by

$$
\sum_{i=1}^{I} N_{i}=N
$$

The total population in the economy, $N>0$, is exogenously given.

The national capital market clearing condition determines the rate of return on capital and the intermediate good market clearing conditions determine $P_{i j}$ in each region. With $P_{i j}$ in hand, we can fix the value of the efficiency wedge. Because the amenity is exogeneous and the labor wedge depends only on $N_{i}$, we can determine the equilibrium instantaneous indirect utility in each region for a given population distribution. Finally, $I+1$ equations (10) and (11) determine the population distribution, $N_{i}$, and the utility level in the economy, $\bar{u}$. While there can be multiple equilibria, we focus on stable equilibrium, that is $\mathrm{d} u_{i} / \mathrm{d} N_{i}<0$ for all $N_{i}>0$ (see Appendix (B) for details).

Intuitively, the equilibrium level of population results from the balance between agglomeration and dispersion forces. A high level of revenue-based productivity promotes

\footnotetext{
${ }^{7}$ Efficiency wedge, including relative prices, is treated as exogenous in our counterfactual simulations. Including some economies of agglomeration through which regional sizes affect productivity in the region enhances agglomeration. The distribution of population then gets skewed and the indirect utility level rises according to the strength of the external effects. Although we have performed some regresssions of TFPR on population to identify the strength of the agglomeration effects, we have failed to find out robust relationships between TFPR and population. For example, regressing $\log P_{i j} A_{i j}$ on $\log N_{i}$ one obtains a coefficient of 0.034 with a White standard error of 0.113 . If we specify an endogenous efficiency wedge as $P_{i j} A_{i j}=\tilde{P A_{i j}} N_{i}^{0.02}$ à la Desmet and Rossi-Hansberg [11] and conduct simulations equalizing some wedges, we unsurprisingly observe that equilibrium population distribution exhibits concentration and the indirect utility rises without any change of our qualitative results.
} 
agglomeration since only a marginal increase in labor supply can earn high income in that region. Amenity-rich regions also attract residents. Dispersion forces are comprised of two distinguished channels. First, a larger region involves higher urban costs, that is, $\mathrm{d}\left(T L R_{i} / N_{i}\right) / \mathrm{d} N_{i}>0$ and $\mathrm{d}\left(T C C_{i} / N_{i}\right) / \mathrm{d} N_{i}>0$, which we confirm later. Second, increasing population leads to magnifying labor market friction that appears in labor wedge if $\iota<0$ and $\tau>0$. The labor wedge itself affects the magnitudes of both the agglomeration and dispersion forces.

In steady state equilibrium, households and firms optimize, the factor markets clear, and land is allocated to people with the highest bid. Note that an equilibrium allocation does not generally coincide with optimal one because migration behavior of households causes externalities and there is no planner nor competitive developer to internalize such externalities.

\section{Data and Calibration}

We calibrate our model to the Japanese regional data and implement counterfactual simulation to uncover the effects of each wedge (efficiency or labor wedge, or amenity) in each sector on population distribution. We begin with a description of the variables and parameters used in the counterfactual exercises.

\subsection{Data description}

The purpose of the counterfactual simulation is to illustrate which wedge governs the spatial distribution of population observed in Japan. For this exercise, we use Regional-Level Japan Industrial Productivity (R-JIP) Database 2014 provided by the Research Institute of Economy, Trade and Industry, the Annual Report on Prefectural Accounts (ARPA) published by Cabinet Office, Government of Japan, and the Housing and Land Survey (HLS) given by Statistics Bureau, Ministry of Internal Affairs and Communications.

The R-JIP data is consistent with the 1993 System of National Accounts and is comparable with the EU KLEMS project. Industries are classified at 23-industry level of detail between 1970-2009. The labor input incorporates human capital that varies in age, educational attainment, and sexes over observations by a calculation that all types of workers are translated into unskilled equivalent unit with weights based on wages. We normalize aggregated labor input per capita to one fourth on average to ensure $h_{i j t} \in(0,1)$.

We use data from the ARPA for final demand. As a spatial unit, we employ prefectures mainly because of data availability. Among 47 prefectures, we omit five prefectures, Shizuoka, Hiroshima, Tokushima, Kochi, and Saga, due to the lack of information for the imputed rents of housing services enjoyed by owner-occupiers, and set the number of the regions $I=42$. All data in the ARPA are measured in constant price deflated by the ratio of nominal output to real output in the R-JIP database.

The total land rent is inferred by the imputed rents of housing services. Assuming that there is no difference between rental housing and owner-occupied housing, we divide the imputed rents by homeownership rates, which come from the HLS data, and use it as the total land rent. ${ }^{8}$ From (5), we obtain the total commuting cost by doubling the total land rent.

The measure of consumption per capita $c_{i}$ is consumption net of urban costs, which are land rent payments and commuting costs. The consumption includes both private and

\footnotetext{
${ }^{8}$ We calculate the homeownership rate except in 2003 and 2008 by using linear interpolation.
} 


\begin{tabular}{lll} 
& GLM & OLS (in log) \\
\hline constant & $1.624(0.058)$ & $-2.793(0.592)$ \\
population & $-6.629 \times 10^{-8}\left(1.110 \times 10^{-8}\right)$ & $0.167(0.041)$ \\
\hline residual deviance & 1.283 & \\
AIC & -53.93 & -14.34 \\
Efron's pseudo R & 0.510 & \\
Adjusted R & & 0.278 \\
\hline
\end{tabular}

Table 1: Estimates of the effect of population on land rent per capita.

general government consumption. The urban costs per capita is a triple of the land rent per capita as suggested by (5).

The model is fitted to annual data for the period 2001-2008 as a benchmark case since 2001 is the first year for which imputed rents data are available. The variables are simply averaged over the periods.

We aggregate 23 industries into 4 broad sectors: primary, secondary, construction, and tertiary sectors. Appendix D summarizes the detailed classification. By this aggregation, which is similar to one in Valentinyi and Herrendorf [32], we can investigate the different models typically employed in the literature: tradable (or regional base) and nontradable; primary, secondary, and tertiary; goods versus services (Jorgenson and Timmer [27]; Desmet and Rossi-Hansberg [12]). In Japan, national land use policies conducted over the post war era, called Comprehensive National Development Plan (Zenkoku Sogo Kaihatsu Keikaku), have provided various fiscal supports with the peripheral regions in an effort to reduce spatial inequalities. In particular, the government has given favorable treatments for the agricultural and construction sectors. This is why we treat the construction sector separately from the secondary sector.

\subsection{Estimation and Calibration}

Urban costs, which consist of housing and commuting costs, are one of the dispersive forces working in our model. In estimating urban costs, we use a generalized linear model (GLM) with an inverse link function. ${ }^{9}$ That is, the total land rent per capita, $T L R_{i} / N_{i}$ is drawn independently according to a Gamma distribution with mean $1 / \mu_{i}$ and variance $\mu_{i}^{2}$ such that $\mu_{i}$ is linear in $N_{i} \cdot{ }^{10}$ In this specification, $T L R_{i}$ is positive for all $N_{i}>0$ as long as $c_{i}>0$.

Table 1 presents results of the urban cost estimation with a GLM model and a log-log ordinary least-squares (OLS) regression. Both regressions implies that households residing in a larger region significantly pay higher total land rents per capita. In other words, we observe congestion externalities, which act as a dispersion force. In the following simulations, we employ the GLM model.

In our baseline calibration, we follow Desmet and Rossi-Hansberg[11] and set the disu-

\footnotetext{
${ }^{9}$ Desmet and Rossi-Hansberg[11] and Behrens, Duranton and Robert-Nicoud [4] have run linear models. Although linear models have an advantage in tractability, it may heavily suffer from misspecification when the relationship is not linear. Because dispersive forces play an significant role in shaping urban configurations, we employ a more general model to avoid damages from misspecification.

${ }^{10}$ We select a distribution family under the GLM since population takes a nonnegative value. The modified Park test is also used to select the model. Even if we use an inverse Gaussian distribution, the result will remain unchanged.
} 
tility of labor $\psi=1.4841$ and the utility level $\bar{u}=10$. The remaining parameters are calibrated as follows. For the annual depreciation rate and the time preference, we choose $\delta=\rho=0.05$. We calculate the capital share in the Cobb-Douglas production function by weighted averages of the ratio of the nominal capital cost to the sum of the nominal capital cost and the nominal labor cost. A different sector has a different capital share as noted in Acemoglu and Guerrieri [1] and Valentinyi and Herrendorf [32]. Qualitative results are robust to the choices of these parameters.

We now derive the three wedges. First, as mentioned before, as the efficiency wedge, we use TFPR instead of total factor productivity, and obtain TFPR from the following equation:

$$
\log T F P R_{i j}=\log \left(\frac{P_{i j} Y_{i j}}{H_{i j}}\right)-\theta_{j} \log \left(\frac{K_{i j}}{H_{i j}}\right) .
$$

Data of nominal value added are used as $P_{i j} Y_{i j}$. For later use, we also estimate TFPR and calculate the capital share for the periods from 1972 to $1979 .{ }^{11}$ Second, the labor wedge is derived from (8). We in turn decompose the labor wedge based on (6). The value of $\iota$ estimated by OLS is $\iota=-0.493$ and it is significant at the $5 \%$ level. The negative value of $\iota$ is also consistent with the specification in Desmet and Rossi-Hansberg [11].

Finally, we identify amenity as a residual from the theory. Amenity solves (10) as follows:

$$
\gamma_{i}=\bar{u}-(1+J \psi) \log c_{i}-J \psi \log \psi+\psi \sum_{j} \log \left(1-\tau_{i j}\right) w_{i j}
$$

We substitute (9) into $c_{i},(1),(2)$ and (7) into $w_{i j}$, and the fitted model of GLM into $T L R_{i} / N_{i}$ to obtain $\gamma_{i}$. The estimated levels of amenity are shown in Figure 1. Amenity has a positive correlation to population and is spatially autocorrelated. Regions in suburban areas of three largest cities, Tokyo, Osaka, and Nagoya (Aichi) tend to have a high level of amenity. One interpretation for it is that amenity reflects market potential - the accessibility of a region to demands - which is absent from the model. Another interpretation is that amenity might capture social capital accumulated trough past public good provision by local (prefectural and city level) governments, which tends to be abundant in large cities.

Table 2 gives summary statistics for the estimated wedges and Figure 2 represents the distributions of estimated efficiency and labor wedges (transformed to $1-\tilde{\tau}$ in $\log$ ), for each sector. We can see from the figure that both the efficiency and labor wedges are heterogeneous across sectors. A few comments are in order. First, the primary sector has significantly lower efficiency wedges and lower negative labor wedges than other sectors. Second. the construction sector has higher efficiency wedges and smaller labor wedges. The low labor wedges in these sectors reflect the Japanese government's favorable treatments, which yield a higher efficiency wedge in the construction sector but are not sufficient to make up for lower productivity in the primary sector. Third, the secondary sector has similar efficiency wedges and higher labor wedges in comparison with the tertiary sector. Note also that the secondary sector has a larger variety in the efficiency wedge than the primary and tertiary sectors. Finally, the efficiency wedges of the primary sector in 1970s are higher than that in the 2000s, which reflects higher relative prices of agricultural goods in 1970s than in 2000s. Because of the data availability, we cannot yield the labor wedge as well as amenity for 1970s.

\footnotetext{
${ }^{11} 1972$ is the first year when data of Okinawa are available. The results are unaffected by the choice of the data span.
} 


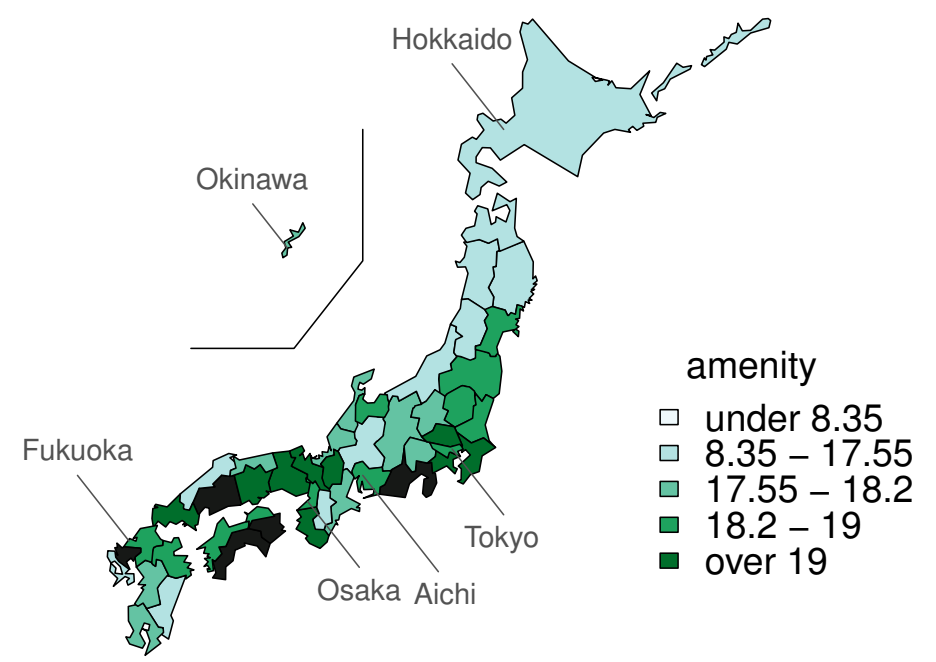

Figure 1: Map of the estimated amenity.

Note: The shaded areas are out of the sample regions.

\begin{tabular}{cccccc} 
& $P_{i j} A_{i j}$ & $\tau_{i j}$ & $\tilde{\tau}_{i j}$ & $\gamma_{i}$ & $P_{i j} A_{i j}$ at $1970 \mathrm{~s}$ \\
\hline Arithmetic Mean & 4.448 & 0.467 & -673.23 & 18.234 & 2.930 \\
Median & 4.535 & 0.956 & -59.92 & 18.160 & 3.102 \\
Standard Deviation & 2.647 & 0.908 & 1175.57 & 0.851 & 1.373 \\
Max & 12.155 & 0.998 & -1.15 & 19.711 & 7.114 \\
Min & 0.393 & -3.211 & -7989.31 & 16.730 & 0.750 \\
\hline
\end{tabular}

Table 2: Descriptive statistics of estimated wedges.
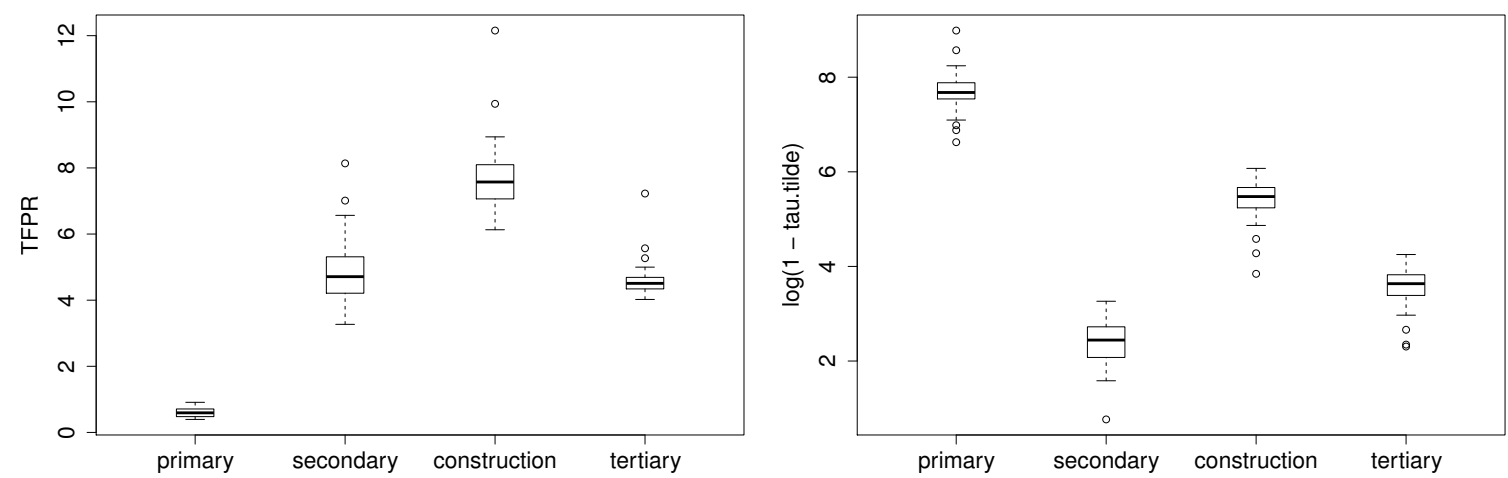

Figure 2: Distributions of estimated TFPRs and adjusted labor wedges $(\log (1-\tilde{\tau}))$. 


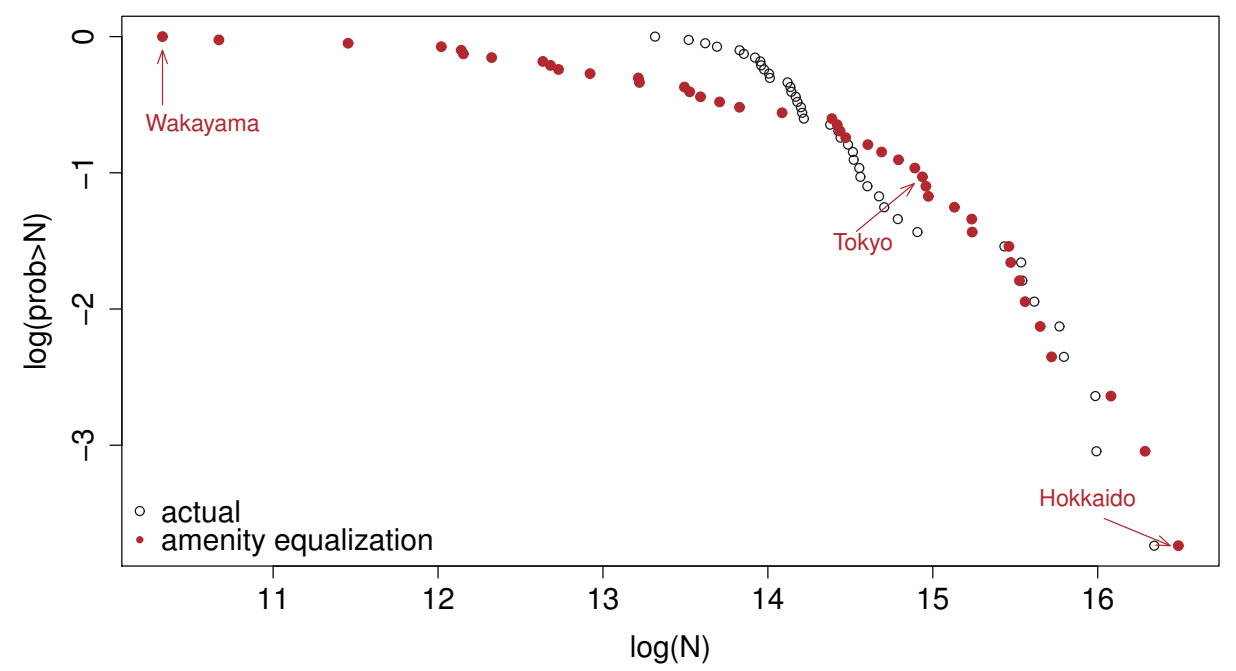

Figure 3: Amenity equalization.

\section{Counterfactual experiments}

To quantify how important are the wedges in determining the spatial structure, this section conducts counterfactual thought experiments eliminating the differences in wedges following Desmet and Rossi-Hansberg [11]. After manipulating particular wedges, we find out new equilibrium population and utility level by using (10) and (11) with nonnegative constraints on population, consumption, and labor supply.

The first scenario eliminates inter-regional differences in amenity. By replacing the actual levels of amenity with the population weighted average level of amenity, we calculate the equilibrium population distribution and the level of utility. Figure 3 shows the resulting distribution. The regions in the lower tail of the size distribution lose their population whereas the sizes of the three largest regions get larger. However, the actual largest region, Tokyo, becomes smaller under the counterfactual because amenity equalization reduces the attractiveness of Tokyo arising from high amenity. In contrast, Hokkaido and Aomori, which locates in the northernmost in Japan, gain the largest population. By equalizing amenity, Hokkaido and Aomori would resolve their disadvantages in market access captured by amenity. The utility level in the counterfactual is higher than that in the baseline by $5.32 \%$.

In the second scenario, we equalize the efficiency wedge across regions within each sector. In so doing, we calculate the average TFPR weighted by population across regions in each sector. This counterfactual highlights the technological gaps between regions. Figure 4 illustrates the result. When we equalize the efficiency wedge across regions, we observe similar changes in the size distribution to the one observed under the amenity equalization: the distribution becomes more concave, and large cities and their neighborhoods lose population whereas regions having less congestion attract large population. Regions with high efficiency wedge, in particular for the manufacturing and agricultural sectors, would unsurprisingly lose their population. Such the regions are likely to have low labor wedges (both $\tau$ and $\tilde{\tau}$ ) in the manufacturing sector. The efficiency wedge equalization increases the utility by $3.69 \%$. 


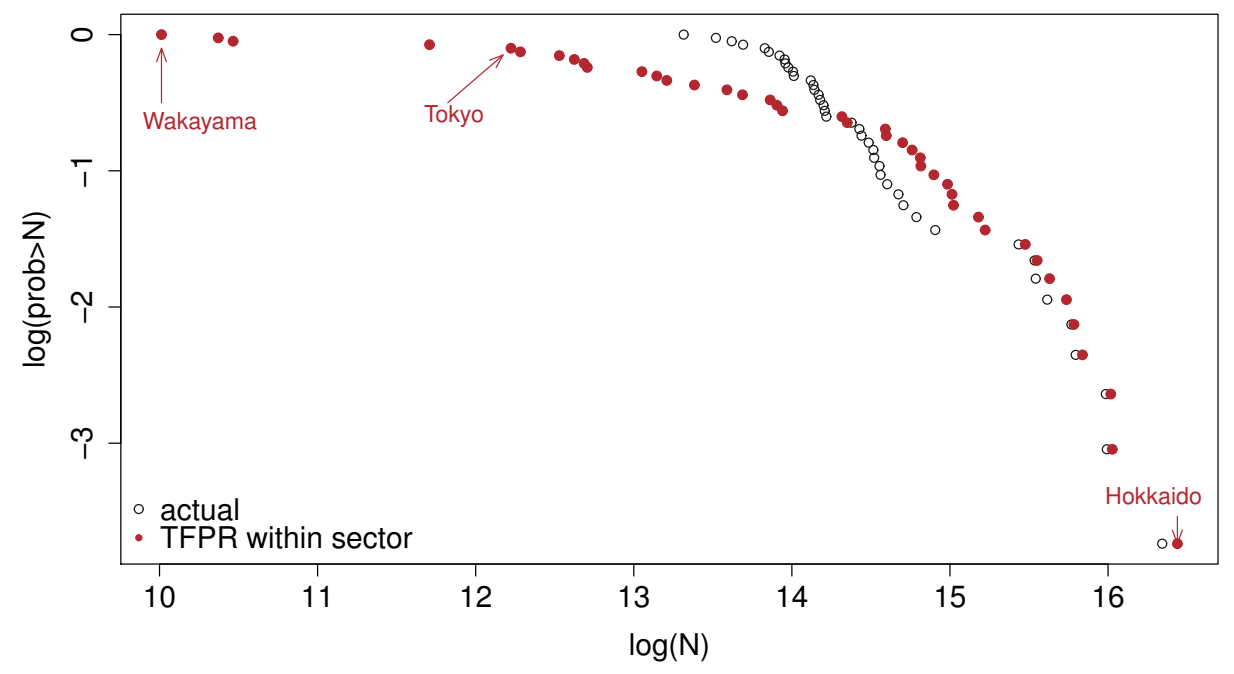

Figure 4: TFPR equalization.

Third, we eliminate differences in the labor wedge unexplained by population, $\tilde{\tau}_{i j}$, across regions within each sector as in a similar manner to the case of the efficiency wedge equalization. Figure 5 shows the result. Changes in labor wedges drastically affect the size distribution: people move from smaller regions to already large regions, and some regions thus disappear $\left(N_{i}=0\right)$, resulting in an extremely concave distribution. After eliminating the labor wedge differences, most people move to the Pacific Belt Zone spreading from Tokyo to Fukuoka, which developed as the central place of the Japanese economy along with rapid industrialization during the 1960s. Those regions have advantages in productivity and amenity, thereby attracting people once the labor wedge is equalized. By this equalization, the utility rises by $11.15 \%$.

We next confirm findings obtained from Figures 3-5 by parametric description of the population distributions in the counterfactual scenarios. Table 3 reports parameters of the population distributions derived in the above counterfactual exercises without regions of zero population (parentheses are values including zero population regions by setting $N_{i t}=1$ for such regions). Pareto exponents are estimated in a way proposed by Gabaix and Ibragimov [21] although Pareto distribution poorly fits with all the cases. The lognormal distribution is also fitted by using Maximum Likelihood methods. The "lognormal location" and "lognormal scale" correspond to the mean and the standard deviation of a natural logarithm of population, respectively. Table 3 gives p-values of KolmogorovSmirnov and Cramér-von Mises tests for the lognormal fitting, which implies that lognormality is not rejected for all the cases excluding nonzero regions.

We can see from the table that all counterfactuals accelerate population agglomeration and increase the variance of population distribution. In particular, we can confirm that the labor wedge equalization has large impacts on the distribution, and nonnegligible number of small regions disappear. The labor wedge predominantly governs the population distribution because currently larger regions have advantages in amenity and TFPR. These findings are consistent with the results shown in Desmet and Rossi-Hansberg [11]. 


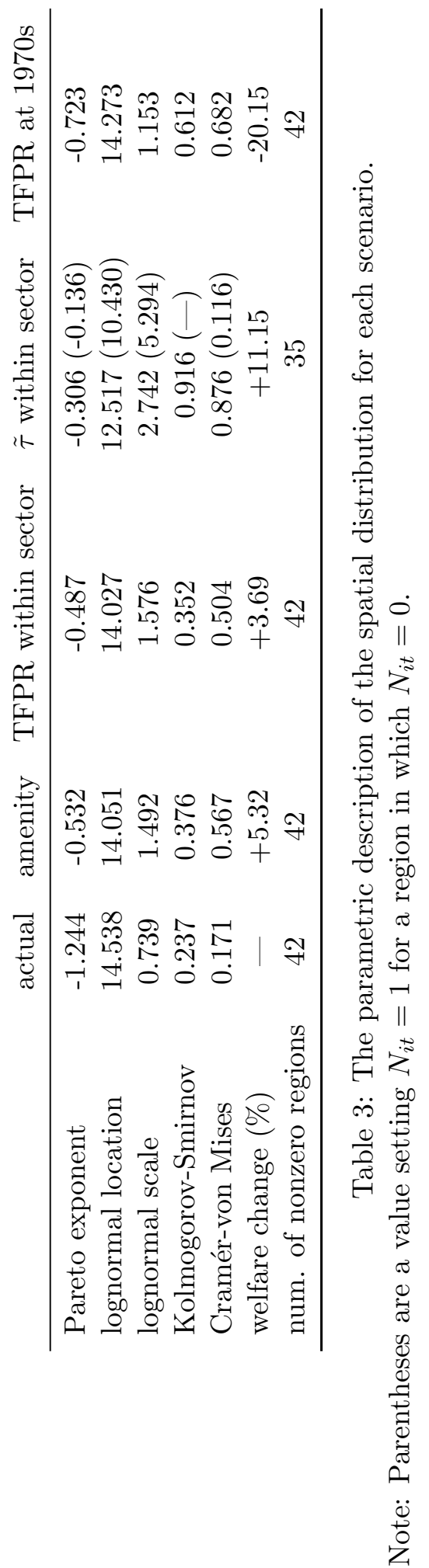




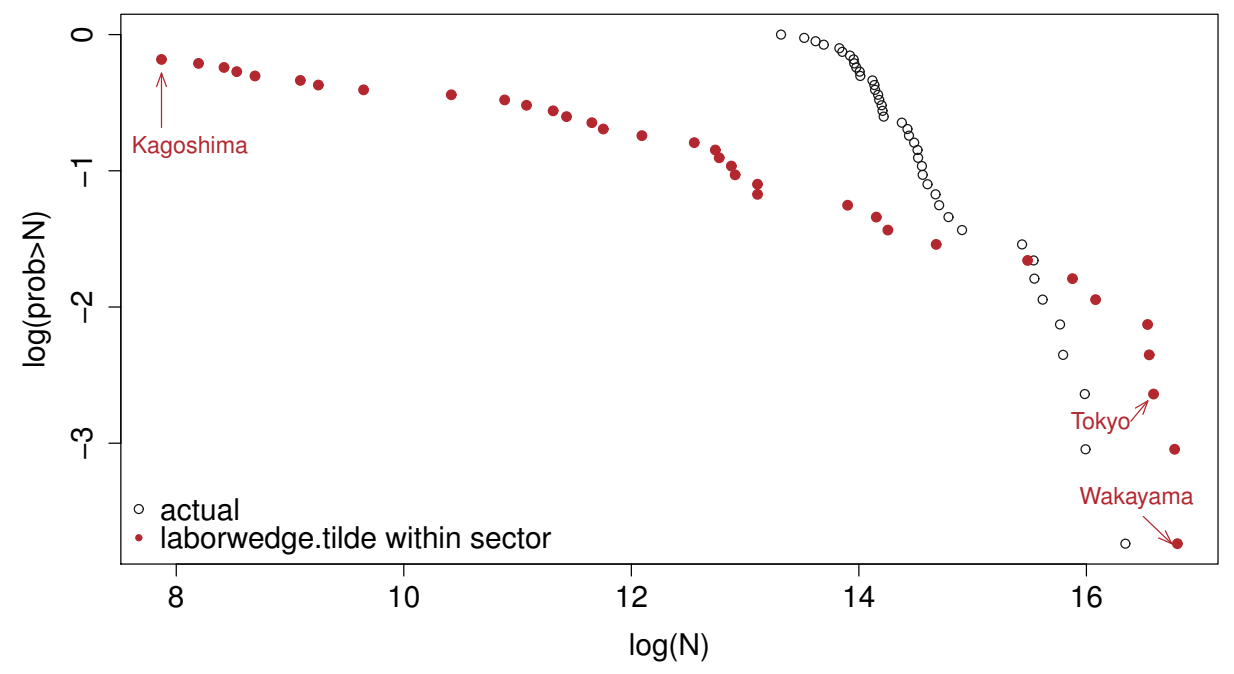

Figure 5: Labor wedge equalization.

\subsection{Impacts of each industry}

Now we investigate the impacts of wedge equalization in one of the four sectors. Figures 6 (a) to (d) show the results: (a), (b), (c), and (d) represent the results of efficiency wedge equalization in the primary, secondary, construction, and tertiary sectors, respectively. We first note that the efficiency wedge equalizaion in the primary and secondary sectors significantly change the population distribution. Second, the efficiency wedge equalization in the construction sector has small effects on population distribution. The tertiary sector has moderate impacts. If we compare these figures to Figure 4, we know that the effects shown in Figure 4 come mainly from the primary and secondary sectors. Surprisingly, the efficiency wedge equalization only in the primary sector increases the population of agricultural regions which have high levels of efficiency wedges. The local labor markets in these regions suffer less distortions, in particular, in the manufacturing sector. The decline in agricultural profitability by the equalization allows people to engage in the less distorted sectors, thereby enhancing utility to live in.

Next, we equalize the labor wedge $\tilde{\tau}$ in one of the four sectors, of which results are summarized in Figures 7 (a) to (d): (a), (b), (c), and (d) represent the results of labor wedge equalization in the primary, secondary, construction, and tertiary sectors, respectively. In this case, the secondary sector has dominant impacts. The primary sector has the second largest impacts. The construction and tertiary sectors have small impacts. If we compare these figures to Figure 5, we can see that the primary driving force resulting in Figure 5 is the secondary sector, which is reinforced by the primary sector.

The results shown in Figures 6 and 7 imply that the secondary sector is the most influential in shaping the population distribution in Japan, which looks reasonable given its role as the leading sector in Japan. It is somewhat surprising that the tertiary sector has small impacts despite of its salient share in GDP (around $45 \%$ in 2013, SNA (National Accounts of Japan)). This would reflect its low productivity as shown in Figure 2. The primary sector also has non-negligible effects on population distribution, which indicates the efficacy of subsidies and favorable treatments by the Japanese government. 
(a)

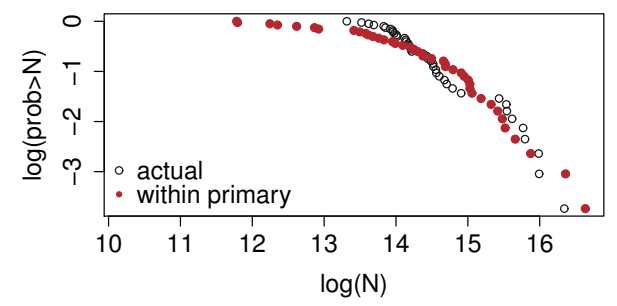

(c)

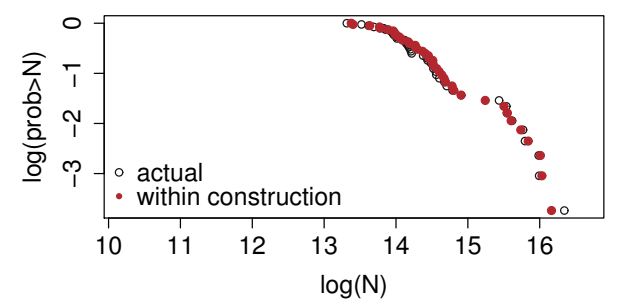

(b)

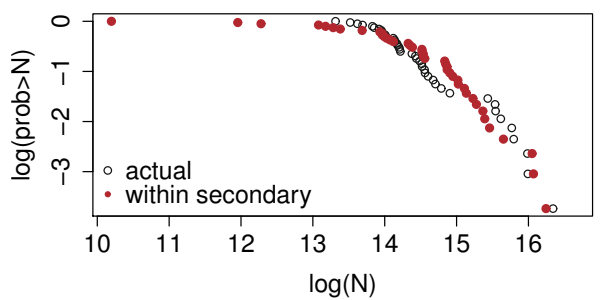

(d)

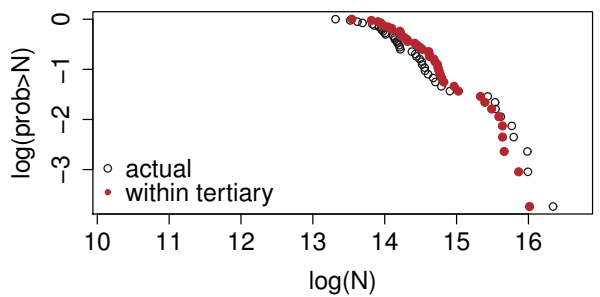

Figure 6: TFPR equalization within a particular sector.

(a)

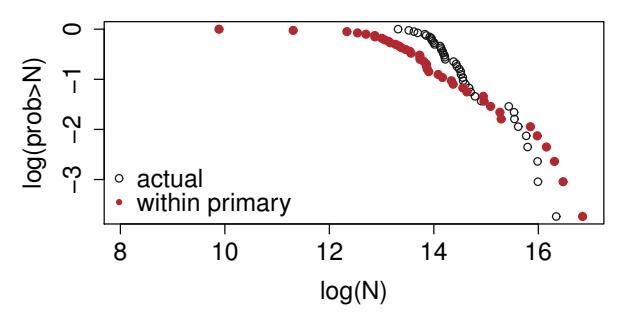

(c)

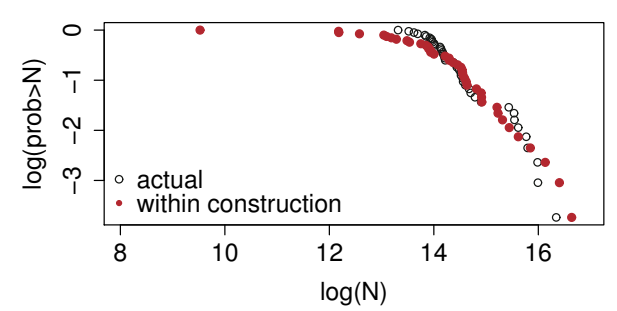

(b)

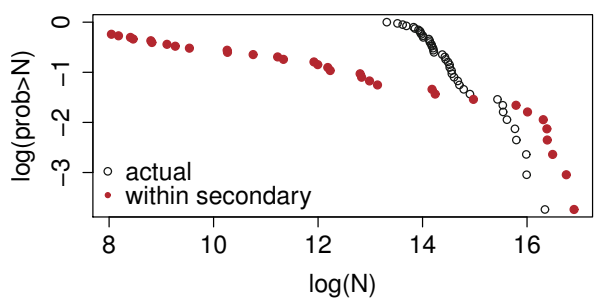

(d)

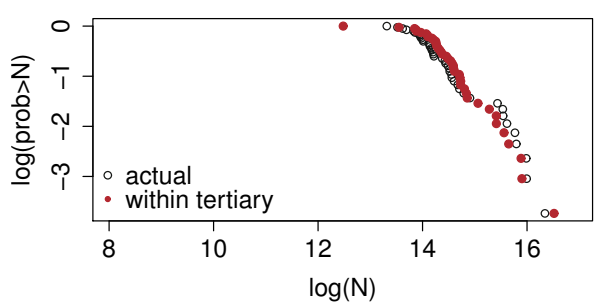

Figure 7: Labor wedge equalization within a particular sector. 


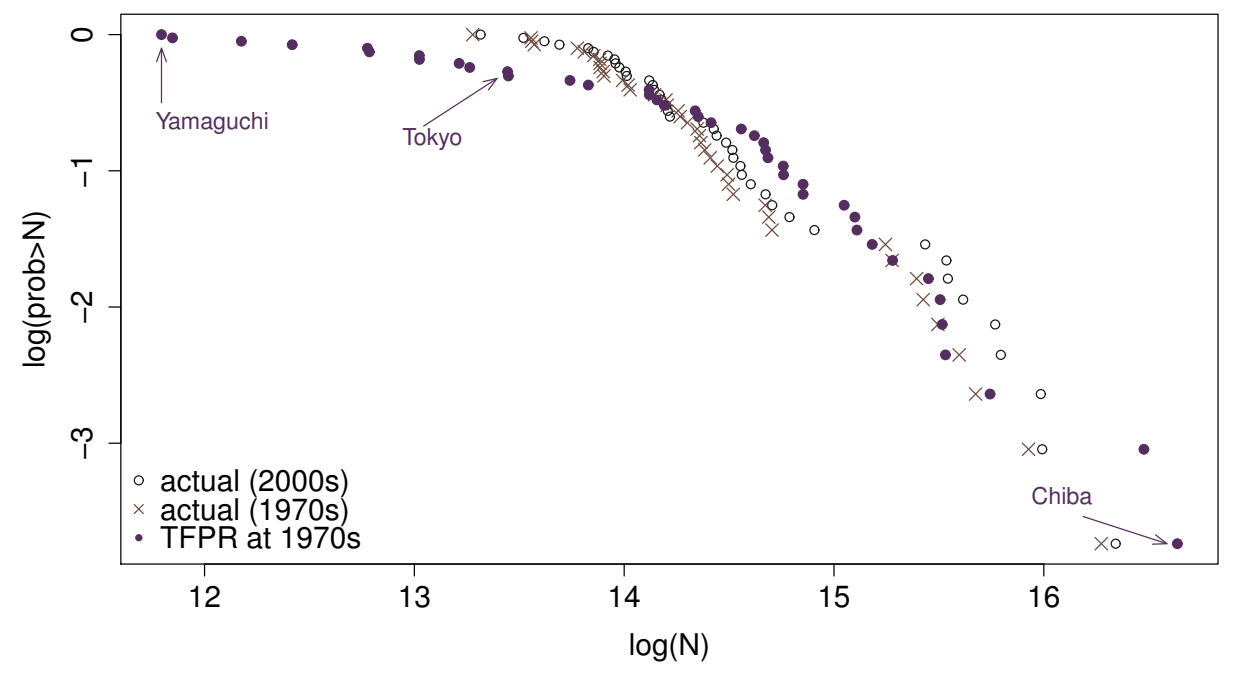

Figure 8: Productivity at 1970s.

\subsection{Productivity restoration}

Finally, we carry out an additional exercise to investigate what makes the spatial transformation over the past four decades in Japan. We substitute TFPR during the 1970s into the model with other wedges and parameters being unaltered. ${ }^{12}$ This implies that the efficiency wedge declines from 4.4 to 2.9 on average (see Table 2), which decreases the utility by $20.15 \%$. Figure 8 shows the resulting distribution along with actual distribution at the present and the past.

In this case, the spatial structure becomes more concentrated, rather than dispersed, than the actual distribution at 1970s. This implies that the evolutions in labor wedge and amenity over the decades have led to spatial concentration while changes in revenuebased productivity have prevented it. It suggests that technological progress or changes in relative demands across sectors would not sufficiently explain the spatial transformation in Japan because such changes should be aggregated to changes in the efficiency wedge.

To illustrate further which industry accounts for the relocation of population, we run scenarios in which TFPRs for only some sectors are replaced by those during 1970s. Specifically, we consider changes in TFPR of only (1) the primary sectors (primary) (2) the secondary sectors including construction (secondary); $(3)$ the tertiary sector (tertiary); (4) the goods sectors (i.e., excluding the tertiary sector) (goods); (5) the tradable goods sectors (i.e., excluding the construction and the tertiary sector) (tradable); and (6) the non-tradable goods sectors (nontradable). Table 4 reports the Spearman's rank correlations between the actual populations and the counterfactual populations.

The transition in the agricultural sector is the most influential on the distribution of population. Once the efficiency wedges of agriculture are restored at the 1970s levels, a large fraction of population will relocate to regions with advantages in agro-industry. In other words, the decline in agriculture over the decades causes the outflows of population from agricultural regions to non-agricultural regions. At the same time, such counterfac-

\footnotetext{
${ }^{12}$ Unfortunately, because of the data availability, we cannot obtain the labor wedge and amenity for 1970 s, and hence we cannot implement similar analysis for them.
} 
tual equilibrium features spatial concentration more than the observed one during 1970s, suggesting that the postwar spatial concentration can not be explained by the changes in agricultural efficiency. To match the observed distribution of population, we thus need to consider other agglomeration forces generated by transformation in labor wedge or amenity over time.

Note finally that if we substitute only TFPR of the construction sector during 1970s, the middle and the upper tail of distribution are fairly unaffected while the small sized regions lose their population. Put differently, not a few peripheral regions have experienced a growth of the construction sectors. This is consistent with the fact that Japanese regional development policies epitomized by the Comprehensive National Development Plan have been substantially directed toward public spending on civil engineer.

\section{Concluding Remarks}

We constructed a model of competitive multisectoral economy with distortional wedges and externalities to sketch which factor affects the observed spatial structure. We then calibrated our model to the Japanese regional data and implemented counterfactual exercises. Our analysis showed that differences in labor wedge are the key player and especially the secondary sector dominates the other sectors in forming the Japanese spatial configuration. In contrast, the tertiary sector plays little role. We also showed that delines in productivity of the primary sector during the past several decades had major impacts on Japanese population distribution.

Although we ignore inter-sectoral externalities in efficiency wedges, multisector setting we develop could incorporate economies of urbanization or coagglomeration (e.g., Ellison, Glaeser, and Kerr [16]; Hsu [26]; Helsley and Strange [23]). Future work may address to incorporate interregional as well as intersectoral linkages. We do not explicitly deal with transaction across regions except migration. Amenity therefore absorbs some sort of linkages, for example, market potential or cross-border commuting which is less likely to be exogenous to the distribution of population. It would be thus promising to endogenize amenity.

\section{References}

[1] Daron Acemoglu and Veronica Guerrieri. Capital deepening and nonbalanced economic growth. Journal of Political Economy, 116(3):467-498, 2008.

[2] William Alonso. Location and land use. Toward a general theory of land rent. Harvard University Press, Cambridge, MA, 1964.

[3] Chun-Chung Au and J. Vernon Henderson. Are chinese cities too small? Review of Economic Studies, 73(3):549-576, 2006.

[4] Kristian Behrens, Gilles Duranton, and Frédéric Robert-Nicoud. Productive cities: Sorting, selection, and agglomeration. Journal of Political Economy, 122(3):507-553, 2014.

[5] Kristian Behrens, Giordano Mion, Yasusada Murata, and Jens Südekum. Spatial frictions. IZA Discussion Papers, (No. 7175), 2013. 


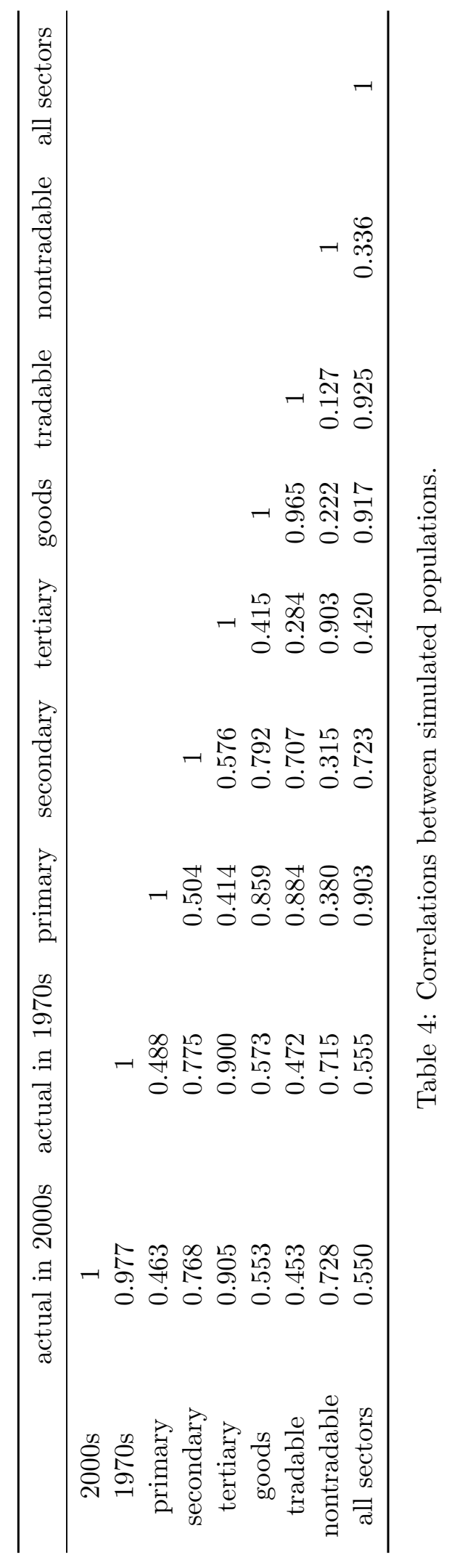


[6] Marcus Berliant and Hiroki Watanabe. Explaining the size distribution of cities: Extreme economies. Quantitative Economics, 6(1):153-187, 2015.

[7] Francisco J. Buera and Benjamin Moll. Aggregate implications of a credit crunch: The importance of heterogeneity. American Economic Journal: Macroeconomics, $7(3): 1-42,2015$.

[8] V.V. Chari, Patrick J. Kehoe, and Ellen R. McGrattan. Business cycle accounting. Econometrica, 75(3):781-836, 2007.

[9] Anton A. Cheremukhin and Paulina Restrepo-Echavarria. The labor wedge as a matching friction. European Economic Review, 68:71-92, 2014.

[10] Harold L. Cole and Lee E. Ohanian. New deal policies and the persistence of the great depression: A general equilibrium analysis. Journal of Political Economy, 112(4):779$816,2004$.

[11] Klaus Desmet and Esteban Rossi-Hansberg. Urban accounting and welfare. American Economic Review, 103(6):2296-2327, 2013.

[12] Klaus Desmet and Esteban Rossi-Hansberg. Spatial development. American Economic Review, 104(4):1211-1243, 2014.

[13] Gilles Duranton. Urban evolutions: The fast, the slow, and the still. American Economic Review, 97(1):197-221, 2007.

[14] Gilles Duranton and Diego Puga. The growth of cities. In Philippe Aghion and Steven N. Durlauf, editors, Handbook of Economic Growth, Vol. 2, pages 781-853. Elsevier, 2014.

[15] Jan Eeckhout. Gibrat's law for (all) cities. American Economic Review, 94(5):14291451, 2004.

[16] Glenn Ellison, Edward L. Glaeser, and William R. Kerr. What causes industry agglomeration? evidence from coagglomeration patterns. American Economic Review, 100(3):1195-1213, 2010.

[17] Lucia Foster, John Haltiwanger, and Chad Syverson. Reallocation, firm turnover, and efficiency: Selection on productivity or profitability? American Economic Review, 98(1):374-425, 2008.

[18] Masahisa Fujita, Tomoya Mori, J Vernon Henderson, and Yoshitsugu Kanemoto. Spatial distribution of economic activities in japan and china. In J. Vernon Henderson and Jacques-François Thisse, editors, Handbook of regional and urban economics, Vol. 4, pages 2911-2977. Elsevier, 2004.

[19] Masahisa Fujita and Takatoshi Tabuchi. Regional growth in postwar japan. Regional Science and Urban Economics, 27(6):643-670, 1997.

[20] Xavier Gabaix. Zipf's law for cities: an explanation. Quarterly journal of Economics, pages 739-767, 1999.

[21] Xavier Gabaix and Rustam Ibragimov. Rank - 1/2: A simple way to improve the ols estimation of tail exponents. Journal of Business \& Economic Statistics, 29(1):24-39, 2011. 
[22] John R. Harris and Michael P. Todaro. Migration, unemployment and development: A two-sector analysis. American Economic Review, 60(1):126-142, 1970.

[23] Robert W. Helsley and William C. Strange. Coagglomeration, clusters, and the scale and composition of cities. Journal of Political Economy,, 122(5):1064-1093, 2014.

[24] J. Vernon Henderson. The sizes and types of cities. American Economic Review, 64(4):640-656, 1974.

[25] Chang-Tai Hsieh and Peter J. Klenow. Misallocation and manufacturing tfp in china and india. Quarterly Journal of Economics, 124(4):1403-1448, 2009.

[26] Wen-Tai Hsu. Central place theory and city size distribution. The Economic Journal, 122(563):903-932, 2012.

[27] Dale W. Jorgenson and Marcel P. Timmer. Structural change in advanced nations: A new set of stylised facts. Scandinavian Journal of Economics, 113(1):1-29, 2011.

[28] Guy Michaels, Ferdinand Rauch, and Stephen J. Redding. Urbanization and structural transformation. Quarterly Journal of Economics, 127(2):535-586, 2012.

[29] Lee E Ohanian. What-or who-started the great depression? Journal of Economic Theory, 144(6):2310-2335, 2009.

[30] Stuart S. Rosenthal and William C. Strange. Evidence on the nature and sources of agglomeration economies. In J. Vernon Henderson and Jacques-François Thisse, editors, Handbook of regional and urban economics, Vol. 4, pages 2119-2171. Elsevier, 2004 .

[31] Esteban Rossi-Hansberg and Mark L. Wright. Urban structure and growth. Review of Economic Studies, 74(2):597-624, 2007.

[32] Ákos Valentinyi and Berthold Herrendorf. Measuring factor income shares at the sectoral level. Review of Economic Dynamics, 11(4):820-835, 2008.

\section{A Labor wedge in a urban system model}

We demonstrate the relationship between the labor wedge and behavior of city developers who internalize Marshallian economies of agglomeration in a system of cities framework.

Consider a production function with labor-augmented externalities $Y_{i j}=A_{i j} K_{i j}^{\theta_{j}}\left[g^{j}\left(\overline{\mathbf{H}}_{i}, N_{i}\right) H_{i j}\right]^{1-\theta_{j}}$ where $\overline{\mathbf{H}}_{i}$ is a $J$-dimensional vector of $\bar{H}_{i j}$. Rossi-Hansberg and Wright [31] employ similar technology. The continuous and differentiable function $g^{j}$ can vary across sectors and allows cross-sectoral externalities $\partial g^{j} / \partial H_{i l} \equiv g_{l}^{j} \neq 0$ for $l \neq j$. The steady-state wage rate is then $w_{i j} \propto g^{j}\left(\overline{\mathbf{H}}_{i}, N_{i}\right)$. Given the national level of utility $\bar{u}$, developer of region $i$ sets labor tax $\tau_{i j}$ and lump-sum tax $T_{i}$ and chooses consumption and hours worked to maximize her land rent revenues: 


$$
\begin{aligned}
\max _{c_{i}, h_{i j}, N_{i}, \tau_{i j}, T_{i},} & T L R_{i}+\sum_{j} \tau_{i j} w_{i j} h_{i j} N_{i}+T_{i} N_{i}, \\
\text { s.t. } u_{i} & =\bar{u}, \\
\rho a_{i}+\sum_{j}\left(1-\tau_{i j}\right) w_{i j} h_{i j}-T_{i} & =c_{i}+3 T L R_{i} / N_{i}, \\
\frac{\psi c_{i}}{1-h_{i j}} & =\left(1-\tau_{i j}\right) w_{i j} .
\end{aligned}
$$

The first constraint means that the regions are small open. The second constraint is the budget of households which differs from our benchmark model because land rents are not transferred to households. The last constraint captures the households' optimization. The developer knows $\bar{H}_{i j}=h_{i j} N_{i}$.

The first-order condition after some manipulation characterizes the optimal tax rate on labor at sector $j$ :

$$
\tau_{i j}=-\frac{g_{j}^{j} H_{i j}}{g^{j}}-\sum_{l \neq j} \frac{w_{i l}}{w_{i j}} \frac{g_{j}^{l} H_{i l}}{g^{l}} .
$$

That is, the labor wedge consists of a Pigouvian subsidy that internalizes the Marshallian externalities depending on the own elasticity and the cross elasticities weighted by relative wages, which varies with population. Without any external effects of labor supply, the labor tax equals zero.

The externalities of population $\partial g / \partial N$ affect the level of the lump-sum tax. In our model, amenity absorbs this external effect.

\section{B Stability and computation}

In our environments, equilibrium is not necessaliry stable nor unique. This appendix discusses the stability and the computation at the simulations.

To examine stability of equilibrium, we check the marginal effect of population on indirect utility, $\mathrm{d} u_{i} / \mathrm{d} N_{i}$, around the equilibrium. This derivative captures the trade-off between agglomeration and dispersion forces. The dispersion forces work through the urban costs, $\mathrm{d}\left(T L R_{i} / N_{i}\right) / \mathrm{d} N_{i}>0$, and through labor wedge, $\mathrm{d} \tau_{i j} / \mathrm{d} N_{i}>0$ for $\tau_{i j}>0$ provided that $\iota<0$. A higher labor wedge fuels a labor-tax-equivalent distortion and therefore lowers the utility. For a negative labor wedge $\tau_{i j}<0$, which is often observed in agricultural sectors, an increase in population rather reduces a subsidy-equivalent distortion, thereby acting as an agglomeration force (more precisely, the agglomeration force prevails when the subsidy exceeds capital income). The equilibrium can be unstable where the agglomeration force dominates the dispersion forces. Such unstable equilibrium tends to occur when $N_{i}$ is fairly small (typically $N_{i}<1000$ ). The utility $u_{i}$ displays inverted U-shape relationships to $N_{i}$, analogous to the models of system of cities, for plausible parameters.

The derivative of utility is

$$
\frac{\mathrm{d} u_{i}}{\mathrm{~d} N_{i}}=\frac{\psi \iota}{N_{i}}\left[\frac{\sum_{j} \frac{w_{i j}+\rho \kappa_{i j}}{\left(1-\tau_{i j}\right) w_{i j}}-J}{1+\psi \sum_{j} \frac{w_{i j}+\rho \kappa_{i j}}{\left(1-\tau_{i j}\right) w_{i j}}}\right]-\frac{2(1+J \psi)}{\sum_{j}\left(w_{i j}+\rho \kappa_{i j}\right)-2 T L R_{i} / N_{i}}\left(\frac{\mathrm{d} T L R_{i} / N_{i}}{\mathrm{~d} N_{i}}\right) .
$$


The second term is negative and induces a dispersion force through urban costs. The first term captures the external effects of population on labor wedges, and its sign is ambiguous and depends on the signs of labor wedges. The overall impacts of population, $\mathrm{d} u_{i} / \mathrm{d} N_{i}$, is thus ambiguous.

An interior equilibrium satisfying (10) is given by

$$
2 \frac{T L R_{i}}{N_{i}}=\sum_{j}\left(w_{i j}+\rho \kappa_{i j}\right)-\left[1+\psi N_{i}^{-\iota} \sum_{j} \frac{w_{i j}+\rho \kappa_{i j}}{\left(1-\tilde{\tau}_{i j}\right) w_{i j}}\right] N_{i}^{\frac{J \psi \iota}{1+J \psi}} \exp \xi_{i}
$$

where

$$
\xi_{i}=\frac{\bar{u}-\gamma_{i}-\psi \sum_{j} \log \left\{\psi /\left[\left(1-\tilde{\tau}_{i j}\right) w_{i j}\right]\right\}}{1+J \psi} .
$$

Equation (13) is nonlinear in $N_{i}$ unless $\iota=0$ and thus one cannot explicitly have the equilibrium populations. To obtain stable equilibrium configuration, we calculate equilibrium allocation the following steps. First, for a given level of the common utility $\bar{u}$, which is initially choosen to be 10, we compute population in all regions according to (13) subject to nonnegative constraints on variables (in particular, $N_{i}>0$ and $c_{i}>0$ ). If there is no interior equilibrium, we set $N_{i}=0$. To exclude an equilibrium that belongs to unstable one, we then evaluate the first derivative 12. If there is a region $i$ with $\mathrm{d} u_{i} / \mathrm{d} N_{i}>0$, we perturb the initial value of population and recalculate interior equilibrium population. Finally, we continue to change the common utility until the sum of the obtained population equals to the actual total population (equation (11)).

\section{Explanatory power of labor wedges on population}

This section discusses the identification and the variations of wedges to clarify the differences between Desmet and Rossi-Hansberg [11] and our specifications. Desmet and Rossi-Hansberg compute 'excess friction' which corresponds to $\tilde{\tau}$ in our model by the following equation:

$$
\log \tau_{i}-\frac{1}{2} \log N_{i}=(\text { constant })+\tilde{\tau}_{i} .
$$

Labor wedge in our specification can be rearranged as follows:

$$
\log \left(1-\tau_{i j}\right)-\iota \log N_{i}=\log \left(1-\tilde{\tau}_{i j}\right),
$$

with $\iota=-0.493$.

In Desmet and Rossi-Hansberg, excess friction $\tilde{\tau}$ accounts for substantial variations of population particularly if there are minor variations in $\tau$. Indeed, more than $70 \%$ of city-size differential is explained by the variation in $\tilde{\tau} \cdot{ }^{13}$ On the other hand, in a single sector version of our model (i.e., $J=1$ ), the adjusted labor wedges are orthogonal to population by construction.

$\tilde{\tau}$ in our main specification can exploit variations across sectors within a region in labor wedges that do not obviously correlated with regional population. Figure 9 shows that neither wedge in a sector appears to be closely associated with population. While $\tilde{\tau}$ plays a prominent role in explaining the shape of population distribution shown in Section 4, this is not driven by construction of labor wedge since $\tilde{\tau}$ does not absorb much of cross-regional variations in population.

\footnotetext{
${ }^{13}$ These statements are pointed out by Tomoya Mori.
} 

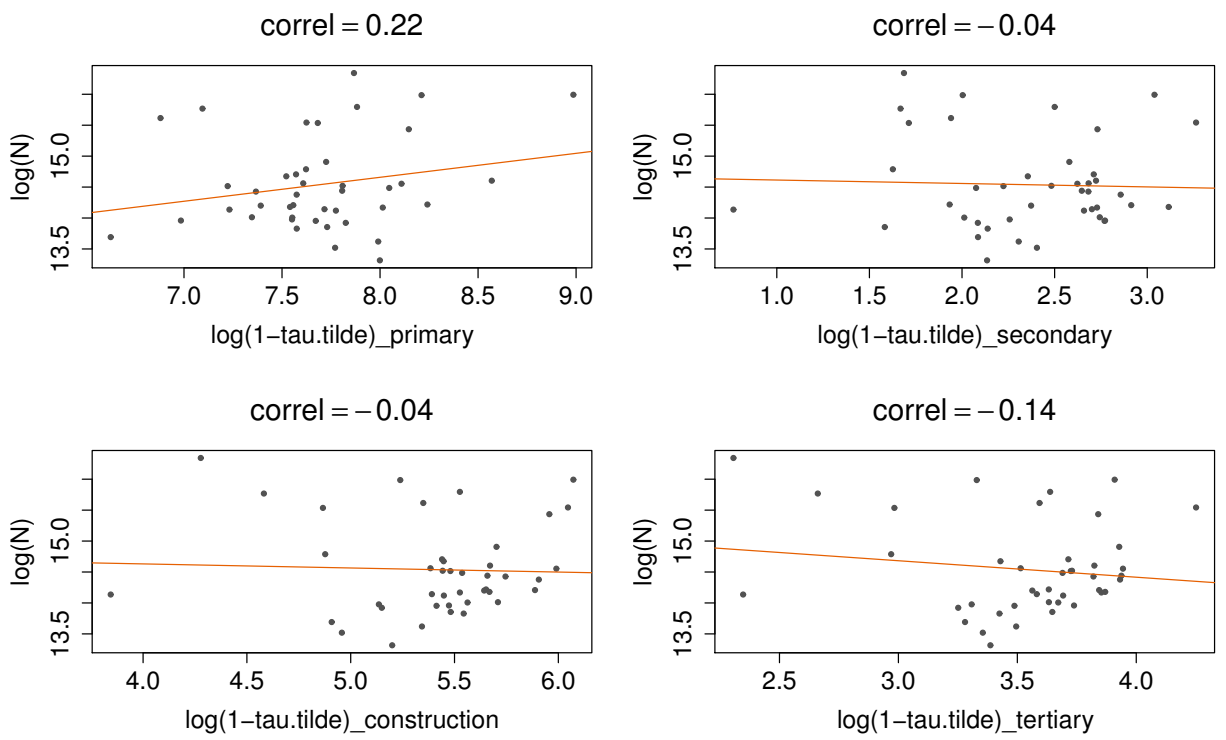

Figure 9: Labor wedge in each sector $\log \left(1-\tilde{\tau}_{i j}\right)$ has little systematic correlation with population.

\section{Sector assignment}

The four sectors focused in the paper contain the following sectors:

- Primary: Agriculture, Forestry, and Fishing.

- Secondary: Mining: Manufacturing; Electricity, Gas, and Water Supply.

- Construction.

- Tertiary: Wholesale and Retail Trade; Finance and Insurance; Real Estate; Transport; Information and Communication; Service Activities; Producers of Government Services.

The R-JIP database ensures an additive consistency property of the real variables. 